\title{
Multiple meningiomas in different neuroaxial locations: report of a rare case
}

\author{
Gopal Raman Sharma ${ }^{1,2}$, Sameer Aryal', Ramchandra Shrestha', Alok Deo', Rakesh Pathak ${ }^{3}$ \\ 'Department of Neurosurgery, Dirghayu Guru Hospital, Chabahil, Kathmandu, Nepal \\ 2Department of Neurosurgery, Nepal Mediciti Hospital, Bhaisepati, Lalitpur, Nepal \\ ${ }^{3}$ Department of Pathology, Dirghayu Guru Hospital, Chabahil, Kathmandu, Nepal
}

ABSTRACT

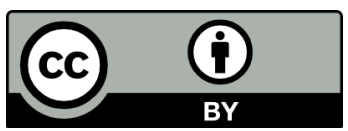

This work is licensed under a Creative Commons Attribution 4.0 Unported License.

We report a rare case of multiple meningiomas in a 74 year old female who was brought to the hospital with spastic paraparesis and MRI of spine and brain revealed multiple enhancing meningiomas in brain and spines. The spinal intradural extramedullary (IDEM) meningioma at C7-D1 level was excised which had caused paraparesis and postoperatively patient became symptom free. We will discuss about the incidence, symptomatology, investigations and management of multiple meningiomas in different neuroaxial compartments at the same period of time and will review the literature.

\section{KEYWORDS}

Concurrent, Craniospinal, Meningiomas, Multiple, Neuroaxial

\section{INTRODUCTION}

1-3\% of cerebral meningiomas are multiple, but multiple spinal meningioma are rare. ${ }^{1}$

Multiple meningiomas are usually associated with neurofibromatosis types 2(NF2). . $^{3}$ Multiple meningiomas occurring in different neuroaxial locations may be found in patients having NF2 ${ }^{4}$, however multiple meningiomas co existing in cranial and spinal areas at same time without a feature of NF2 is very rare ${ }^{5}$ and only five cases have been reported in the literature. $2,4,6,7,8$

\section{CASE REPORT}

A 74 year old, right handed lady, was brought to neurosurgery OPD with the history of weakness of both lower limbs, numbness in lower limbs and incontinence of urine for last 20 days which was gradual onset. On examination she was fully conscious and oriented and all cranial nerves were functioning. She had paraparesis of MRC grade I (Medical research council) in right lower limb and grade III in left lower limb with decreased sensation below nipples. She had incontinence of urine. She had no clinical features of NF2. Cranial and spinal MRI scanned showed multiple meningiomas in brain as well as in spines. MRI of brain showed two well defined extra axial oval shaped lesions measuring about $7.5 \times 10.4 \mathrm{~mm}$ and about $13.4 \mathrm{X}$ $15.2 \mathrm{~mm}$ seen overlying the right parietooccipital convexity
(Figure 1a); both lesions demonstrated post gadolinium enhancement. MRI of cervical spines showed two IDEM lesions measuring about $6.3 \times 8.5 \mathrm{~mm}$ at $\mathrm{C} 2$ level on right side and $12.1 \times 23 \mathrm{~mm}$ at C7-T1 level and both lesions were homogenously enhanced (Figure 1b\&c).

Cervical IDEM mass at C7-T1 level had compressed and pushed the spinal cord anteriorly causing profound neurological deficit. We decided to operate and remove the symptomatic lesion of C7 -T1 level. We performed standard laminectomy of C6 to T1, midline durotomy and removal of IDEM mass which was moderately vascular, attached to the inner surface of dorsal and right lateral part of dura. After Simpson's grade II excision of lesion water tight dural closure was carried out. Wound was closed in anatomical layers after having proper hemostasis. Postoperative neurological recovery was dramatic and patient was discharged on 10th postoperative day with full neurological recovery. Postoperative MRI of spines showed no residual mass at C7-T1 level (figure 1d\&e) Histological examination revealed transitional meningioma (WHO grade I) (figure.2a\&b). Two cranial and one spinal meningiomas which were asymptomatic at present are being watched regularly at neurosurgery OPD with clinical and radiological monitoring.

\section{*Corresponding Author}

Gopal Raman Sharma, Department of Neurosurgery, Nepal Mediciti Hospital Sainbu, Lalitpur, Nepal | Email: gopalramansharma@gmail.com

Phone no: +977-1-421776655 | GPO BOX No: 19429 


\section{DISCUSSION}

Intracranial meningioma constitutes about 15-20\% of all primary CNS tumor and out of them only 1-3\% are multiple meningiomas. ' Similarly, about 25\% of all spinal tumors constitute spinal meningioma and mostly they are intradural extramedullary (IDEM) location; multiple spinal meningiomas are rare entity. ${ }^{8}$

Literature reveals that about $40-58 \%$ of patient with NF2 may develop intracranial and 20\% spinal meningiomas respectively, however meningiomas in these patients are often multiple, slow growing and benign. ${ }^{8}$ Relationship between isolated multiple meningiomas and NF2 is still unclear. ${ }^{3}$

Multiple meningiomas in the absence of NF2, is rare and usually occur in a single anatomical location ${ }^{5,9}$, and concurrent multiple meningiomas in different neuroaxial compartments are even rare and only five cases have been reported in literature $2,4,6,7,8$ and our case being the 6 th one.

Few cases of Spinal metastasis who were previously operated for malignant intracranial meningiomas have been reported in literature ${ }^{10}$ and similarly there are few case reports of previously operated intracranial meningioma who later on developed spinal meningiomas;10,11,12; these dissemination might be attributed to via CSF or blood pathways. $^{5}$

How does multiple meningiomas occur concurrently in different cerebrospinal axis in a person? Is a matter of controversy, though there are possible hypothesis of dissemination via CSF, blood or multiple focal origin or genetic predisposition are there and that needs to be proved in future studies. ${ }^{5,12}$

There were five reported cases of simultaneous occurrence of multiple meningiomas in brain and spines dated from 1973 to $2015.2,4,6,7,8$ All cranial meningiomas in these cases were supratentorial except Bhatoe's case ${ }^{7}$ and all spinal meningiomas were IDEM and at dorsal spines; Except Roda's case ${ }^{6}$ only symptomatic single lesion were operated at one time, all lesions were benign, either meningoepitheial or psamommatous in histological characters.(Table. 1)

Treatment of these multiple meningiomas depends on the symptomatology of the patients and radiological features of meningiomas; symptomatic and larger one should be dealt first.

Surgery is the best treatment option since majority of these meningiomas are benign. Surgical excision followed by radiation therapy should be recommended if histology shows the features malignancy.,10

Small meningiomas, usually not causing mass affect and without perilesional edema should be awaited and have regular follow up with clinical and radiological monitoring.

\section{CONCLUSION}

Co-existing of multiple meningiomas in different neuraxial compartments without evidence of NF2 is very rare.

Multiple meningiomas in female, young age and if they are associated with NF2 should be advocated for cranial and spinal radiological evaluation.

Symptomatic meningiomas should be dealt first followed by others and small, asymptomatic meningiomas should be monitored clinically and radiologically.

\section{REFERENCES}

1) Geuna E, Pappada G, Regalia F, Arrigoni M. Multiple meningioma. report of nine cases. Acta Neurochir.1983;68(1-2):33-43

2) Shukla SK, Tridevi A, Sharma V, Sing K. Co-existing cranial and multiple spinal meningiomas in a child -report of a case. $J$ Neurocol. 2011;102(1):115-9

3) Stachowicz-Stencel T, Synakiewicz A, Bien E, AdamkiewiczDrozynsk E, Wybiezalska-Dubaniewicz M, Balcerska A. Multiple primary craniospinal tumors in a 13 year old female with neurofibromatosis type 2 management strategy. childs Nerv Syst. $2011 ; 27(1): 175-8$

4) Sedzimir $C B$, frazer $A R$, Robert JR. Cranial and spinal meningiomas in a pair of identical twin boys. J Neurol Neurosurg Psychiatry. 1973;36(3):368-76

5) Zumkeller $M$, Seifert $V$, Dietz $H$. Multiple meningiomas in different compartments of cerebrospinal axis. Nervenarzt. 1992;63(12):763-7

6) Roda JM, Bencosme JA, Pervez-Higuevas A, Fraile M. Simultaneous multiple intracranial and spinal meningiomas. Minimum Invasive Neurosurg. 1992;35(3):92-94

7) Bhotoe HS. Simultaneous occurrence of multiple meningiomas in different neuroaxial compartments. Neurol India. 2003;1(2): 263-5

8) Jain SK, Vijay sundar I, Sharma V, Goel R.S, Prasanna KL. Multiple spinal and cranial meningiomas: a case report and review of literature. Asian J Neurosurg. 2015;10(2):132-134

9) Drouet A, Guilloton L, Pelissou-Guyotat I, Saint-Pierre G, Ribot C, Sindou M, Deruty R. Multiple intracranial and intraspinal meninglomas successively discovered in the absence of neurofibromatosis; 2cases. Rev Neurol.2001;157(10):1264-9

10) Lee TT, Landry HJ. Spinal metastases of malignant intracranial meningioma. surg Neurol. 1998;50(5): 437-41.

11) Arseni $C$, Dumitrescu L, Carp N. Orbital,Sphenoidal ridge and spinal meningiomas occurring in one patient. Neurochirurgia. 1984;12(3):86-8

12) Kannuki S, Soga T, Hondo H, Matsumoto K, Takada K, Makino A. Co-existence of intracranial and spinal meningiomas-report of two cases. Neurol med chir.1991;31(11):720-4 
Table 1: Clinical details of five reported cases of coexistence of multiple cranial and spinal meningiomas.

\begin{tabular}{|c|c|c|c|c|c|c|}
\hline \multirow{2}{*}{ S.N } & \multirow{2}{*}{ Authors / Years } & \multirow{2}{*}{ Age / Sex } & \multicolumn{2}{|c|}{ Location } & \multirow{2}{*}{ Presentation } & \multirow{2}{*}{ Histopathology } \\
\hline & & & Cranial & Spine & & \\
\hline \multirow{2}{*}{1} & \multirow{2}{*}{${ }^{4}$ Sedzimir et al 1973} & \multirow{2}{*}{$13 / \mathrm{M}$} & \multirow{2}{*}{ Tuberculum sellae } & Cervical & \multirow{2}{*}{$\mathrm{N} / \mathrm{A}$} & Cranial: Not resected \\
\hline & & & & Dorsal & & Spine: Psammomatous \\
\hline \multirow{2}{*}{2} & \multirow{2}{*}{${ }^{6}$ Roda et al N 1992} & \multirow{2}{*}{$50 / \mathrm{M}$} & \multirow{2}{*}{$\begin{array}{l}\text { Suprasellar } \\
\text { falcine }\end{array}$} & \multirow{2}{*}{$\begin{array}{l}\text { Dorsal } \\
\text { dorsal }\end{array}$} & \multirow{2}{*}{$\mathrm{N} / \mathrm{A}$} & Cranial: Meningoepitheial \\
\hline & & & & & & Spine: Meningoepithelial \\
\hline \multirow{2}{*}{3} & \multirow{2}{*}{ 'Bhatoe HS 2003} & \multirow{2}{*}{$35 / F$} & \multirow{2}{*}{$\begin{array}{l}\text { Supratentorial } \\
\text { infratentorial }\end{array}$} & \multirow{2}{*}{$\begin{array}{l}\text { Dorsal } \\
\text { dorsal }\end{array}$} & \multirow{2}{*}{$\mathrm{N} / \mathrm{A}$} & Cranial: Not resected \\
\hline & & & & & & Spine: Psammomatous \\
\hline \multirow{2}{*}{5} & \multirow{2}{*}{${ }^{2}$ Shukla et al 2011} & \multirow{2}{*}{$13 / F$} & \multirow{2}{*}{$\begin{array}{l}\text { Frontal } \\
\text { Parietal }\end{array}$} & \multirow{2}{*}{$\begin{array}{l}\text { Dorsal } \\
\text { Lumbar }\end{array}$} & \multirow{2}{*}{$\begin{array}{l}\text { Focal seizure } \\
\text { Paresthesia }\end{array}$} & Cranial: Not resected \\
\hline & & & & & & Spine: Meningoepithelial \\
\hline \multirow{2}{*}{4} & \multirow{2}{*}{ 8Jain et al 2015} & \multirow{2}{*}{$62 / F$} & \multirow{2}{*}{$\begin{array}{l}\text { Right Frontal } \\
\text { Left Parietal }\end{array}$} & \multirow{2}{*}{$\begin{array}{l}\text { Dorsal } \\
\text { Lumbar }\end{array}$} & \multirow{2}{*}{$\begin{array}{l}\text { Low back pain } \\
\text { Paresthesia }\end{array}$} & Cranial: Not resected \\
\hline & & & & & & Spine: Meningoepithelial \\
\hline \multirow{2}{*}{6} & \multirow{2}{*}{ Present case 2021} & \multirow{2}{*}{$74 / F$} & \multirow{2}{*}{$\begin{array}{l}\text { Right Parietal } \\
\text { Right Occipital }\end{array}$} & Cervical & Paraparesis & Cranial: Not resected \\
\hline & & & & Dorsal & Urinary incontinence & Spine: Transitional \\
\hline
\end{tabular}

Figures:

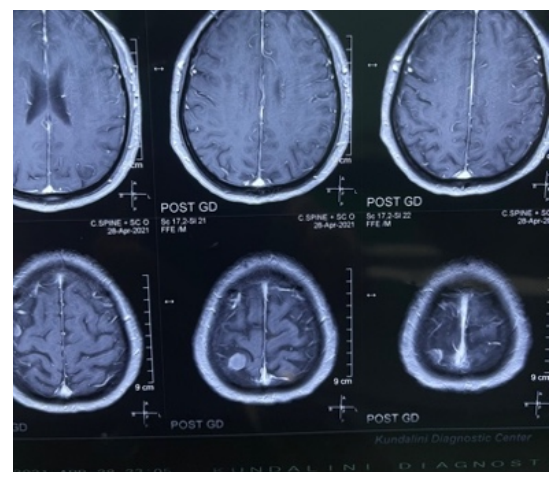

Fig. 1a

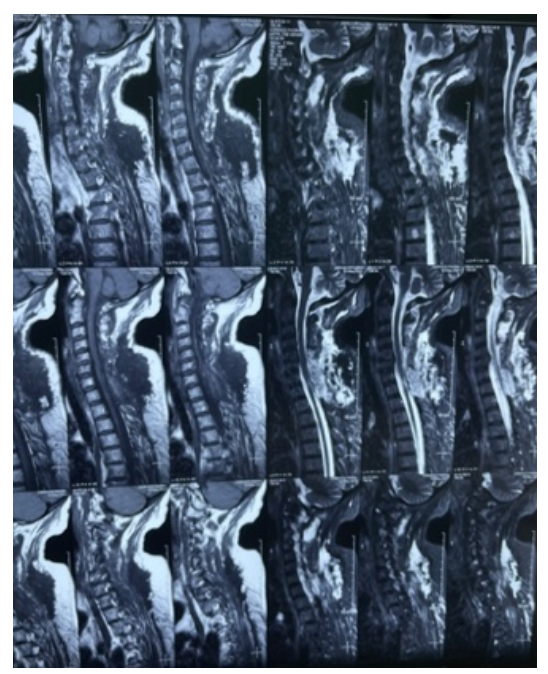

Fig. 1d

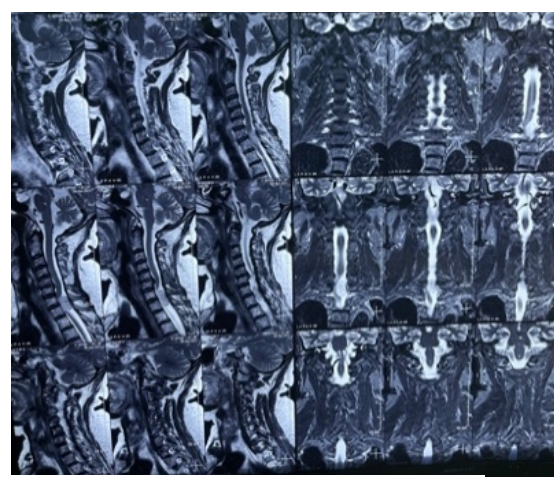

Fig. $7 b$

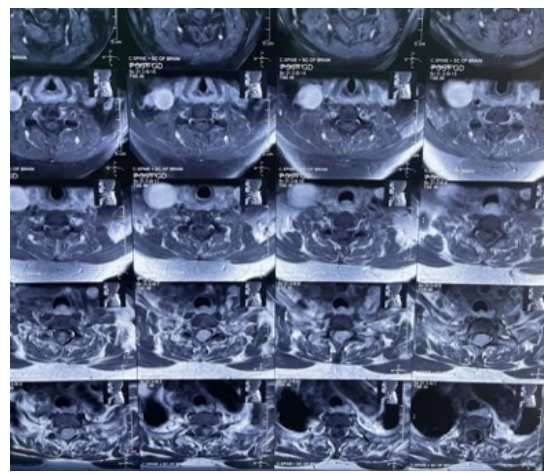

Fig. 1c

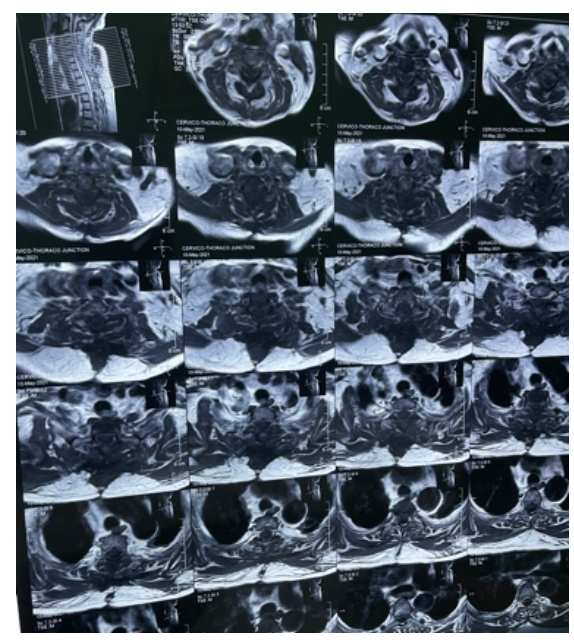

Fig. $7 e$

Figure 1. - Fig. 1a: Contrast MRI of brain with axial cuts showing two oval enhancing extra axial lesions in right parietooccipital lobes; Fig. 1b: T2W2 sagittal MRI of spines dipecting C2 and C7-T1 IDEM lesions; Fig. $1 \mathrm{c}$ : Axial cuts of cervical spines with Gadolinium contrast showing homogenously enhanced lesions at $\mathrm{C} 2$ and C7-T1 level and this second lesion has compressed and pushed the spinal cord anteriorly. Fig. 1 d \& e. Postoperative MRI of cervical spines with contrast show no residual mass of C7-T1 level. 


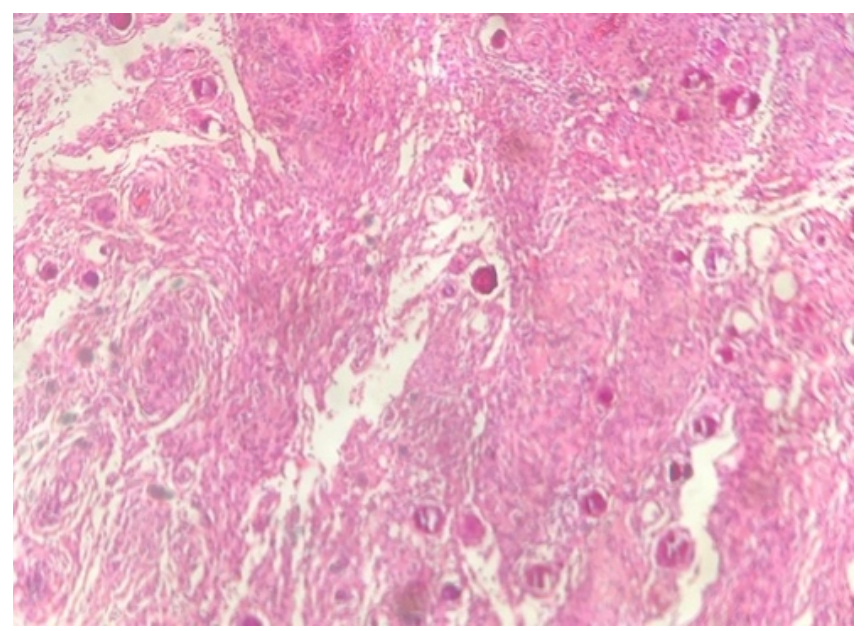

Fig.2a

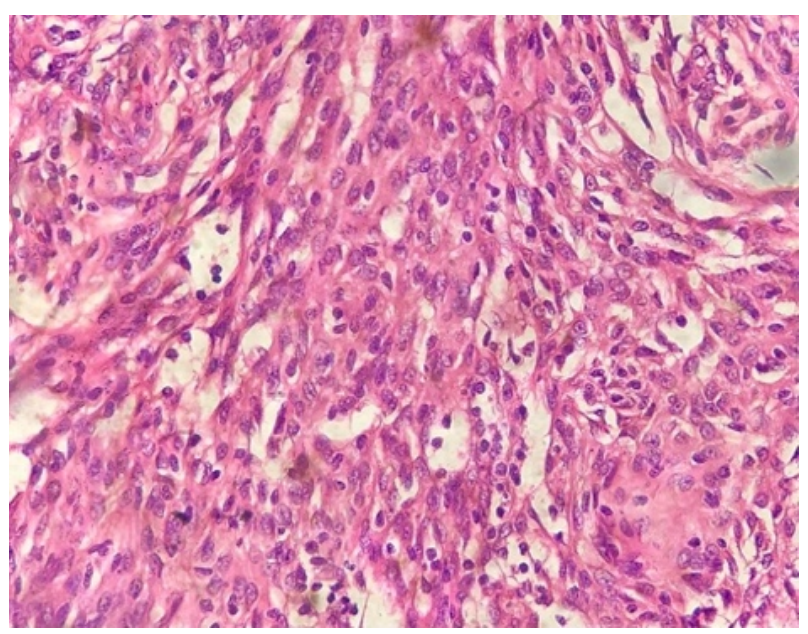

Fig. $2 b$

Figure 2.Microscopic photographs; Fig.2a:(H\&E x 200) \& Fig.2b: (H\&E x 400) show meningoepitheial cells arranged in lobules and whorl patterns with psammoma bodies consistent with transitional meningioma (WHO grade I). 